\title{
APLICAÇÃO DE TÉCNICAS ESTATÍSTICAS PARA ANÁLISE DAS ATIVIDADES DE UM PROCESSO DE ESTAMPARIA DE CHAPAS: ESTUDO DE CASO PARA PREPARAÇÃO DO SISTEMA KANBAN
}

\section{APPLICATION OF STATISTICAL TECHNIQUES FOR ANALYZING THE ACTIVITIES OF A PROCESS OF STAMPING STEEL SHEET: CASE OF STUDY FOR PREPARATION A THE KANBAN SYSTEM}

\author{
Isaac Pergher ${ }^{1}$; Guilherme Luís Roehe Vaccaro ${ }^{2}$ \\ ${ }^{1}$ Universidade do Vale do Rio dos Sinos - UNISINOS - São Leopoldo - Brasil \\ eng.isaac@ hotmail.com \\ ${ }^{2}$ Universidade do Vale do Rio dos Sinos - UNISINOS - São Leopoldo - Brasil \\ guilhermev@unisinos.br
}

\begin{abstract}
Resumo
Este artigo apresenta uma discussão referente a utilização de técnicas estatísticas para subsidiar a análise de pré-implantação de um sistema Kanban, que terá como principal atributo, auxiliar nas atividades referentes à programação da produção e controle de estoque, em uma célula de estamparia. O piloto, realizado com 4 tipos de componentes que apresentam maior demanda, busca avaliar os benefícios de aplicabilidade da ferramenta e também treinar a equipe envolvida. A partir dos resultados fornecidos pelos testes de Análise de Variância e pelo Coeficiente de Variação de cada uma das atividades executadas nas operações de: setup de ferramentas, abastecimento de bobina e manutenção de ferramenta, são desenvolvidas propostas que buscam reduzir a variabilidade nas atividades que apresentam diferenças significativas quando analisam-se fatores como: turno, produto e turno*produto, antes de calcular o número de cartões Kanban do sistema.
\end{abstract}

Palavras-chave: Sistema Kanban de abastecimento; Análise de Variância; Estatística nãoparamétrica.

\section{Introdução}

Considerado o contexto de competitividade e globalização e, mais recentemente, de busca por sustentabilidade e de responsabilidade social e ambiental, as organizações têm buscado eliminar perdas e racionalizar seus processos. Perdas são todas as atividades que geram custo e não adicionam valor ao produto. Logo, devem ser eliminadas dos processos de produção de bens e serviços (ANTUNES et al, 2008). Uma das metodologias difundidas no contexto industrial que busca, de forma incessante, a eliminação das perdas, é o Sistema Toyota de Produção (STP). Originário das fábricas da Toyota pós-guerra, no Japão, este sistema é constituído por uma 'espinha dorsal' na qual se inserem, além de uma filosofia de melhoria incremental e redução de 
desperdícios, diversas abordagens metodológicas e técnicas, dentre as quais se podem citar: Troca Rápida de Ferramentas, Kanban, Poka Yoke, 5S, Padronização da atividade de trabalho, Manutenção Preventiva e Células de Manufatura, focadas em dois pilares básicos, conforme (OHNO, 1997): Autonomação (ou automação com um toque humano) e Just-in-time (JIT).

No pilar JIT, o Kanban tem a finalidade de enviar as informações necessárias para a operacionalização de todo o sistema (OHNO, 1997). O sistema Kanban gerencia a produção tendo duplo objetivo: (i) informar as fases do processo de produção no momento presente; e (ii) agilizar o processo de liberação da produção. Por ser um sistema que puxa a produção, o Kanban informa, aos estágios anteriores do processo de fabricação, a demanda que ocorre no último estágio, que pode ser a expedição, atuando dessa forma, como um elo entre os estágios do processo e a demanda final do produto (CONTADOR et al, 2005). Contudo, o JIT se torna inviável sem o apoio do conceito de Autonomação/zero defeito porque, neste caso, os materiais poderiam chegar na quantidade certa, no local certo e no tempo certo, porém com a qualidade errada. Essa conexão é fundamental para a sustentabilidade do Kanban como sistema de gestão descentralizada da informação de produção. Além disso, dada sua suscetibilidade à ação da variabilidade sobre o sistema, há necessidade de estabelecer nivelamento de demanda e padronização de tempos e operações (ANTUNES et al, 2008) previamente a sua implantação.

A suscetibilidade desse sistema de puxar a produção à variabilidade pode ser observada também no cálculo do número de cartões (ou qualquer outro substitutivo), necessário para desenvolver o Sistema Kanban. O dimensionamento de cartões Kanban entre dois centros de produção, considerando a soma entre Kanban de produção e de transporte pode ser feito segundo (CORRÊA et al, 2001), pela Equação 1:

$$
X=\frac{D\left(T_{e}+T_{P}\right)(1+F)}{C}
$$

onde $X=$ número total de Kanbans; $D=$ demanda do centro consumidor por unidade de tempo; $T_{e}=$ tempo de espera do lote no centro produtor; $T_{p}=$ tempo de processamento do lote no centro produtor; $C=$ tamanho do lote ou capacidade do contêiner (peças por Kanban); $F$ = fator de segurança. Variações sobre essa expressão podem ser obtidas na literatura: (i) considerando-se um tempo único, $\mathrm{T}$, para a realização de um ciclo completo de produção em lugar de $\mathrm{T}_{\mathrm{e}} \mathrm{e} \mathrm{T}_{\mathrm{p}}$ (MARTINS e LAUGENI, 2002; SLACK et al, 1997); e (ii) considerando o fator de segurança como associado também à eficiência de máquina (SLACK et al, 1997). Essas abordagens para o dimensionamento do número de Kanbans apresentam certas particularidades entre si.

Contudo, em geral, é razoável estabelecer que, para calcular o número de Kanbans do sistema, seja necessário construir uma base amostral, formada pelos dados relativos ao processo produtivo e considerando a jornada de trabalho, conforme cada variável que forma o modelo de 
cálculo. Se observados os pressupostos anteriormente descritos, e considerado um ambiente de variabilidade baixa ou não significante, essa atenção pode ser reduzida. No entanto, em ambientes produtivos, nos quais ainda não estão sedimentados os conceitos do STP, que segundo Antunes (1998), objetivam reduzir as variabilidades através de ações nos sistemas de produção, é possível encontrar situações nas quais a variabilidade é significante. Nessas situações, é indispensável a aplicação dos conceitos derivados da estatística descritiva e inferencial, tendo o enfoque na extração de informações que proporcionem um melhor entendimento sobre o contexto, de modo a averiguar se a aplicação de um sistema Kanban é viável.

Com base nas questões apresentadas, o objetivo deste trabalho é propor uma discussão sobre a utilização de técnicas estatísticas para substanciar a análise de pré-implantação de um sistema Kanban. Visa, portanto, estabelecer um link entre a tática e a operação de implantação do sistema Kanban, usando como meio de ilustração e discussão as informações de um estudo de caso, de uso do Kanban como ferramenta de auxílio à programação da produção. O estudo desenvolve-se a partir de um plano piloto que objetiva avaliar os benefícios de aplicabilidade da ferramenta e também treinar a equipe envolvida.

A justificativa da discussão proposta reside no fato de que essa operacionalização nem sempre é abordada em detalhes na literatura de referência, podendo ser geradora de insucesso ou degradação de desempenho quanto à implantação do sistema Kanban. Observa-se que as expressões apresentadas para cálculo de Kanban tipicamente encontradas na literatura não consideram a variabilidade temporal a que o sistema produtivo pode estar submetido. A base de cálculo típica é a média, estratégia adequada se este indicador for representativo do comportamento do sistema, o que não é verdadeiro em ambientes submetidos a níveis significantes de variabilidade (HOPP e SPEARMAN, 2000). Nesse contexto, as conseqüências do dimensionamento inadequado estão ligadas diretamente a conseqüências financeiras e degradação de desempenho do sistema produtivo.

Nas próximas seções são apresentados detalhes sobre o sistema Kanban de abastecimento. Após, relatam-se o métodos e materiais referentes à coleta de dados. Posteriormente, ilustra-se o referencial teórico, constituído pelas ferramentas estatísticas utilizadas e também o estudo de caso, no qual detalhes sobre o processo de estamparia de chapas. Depois são abordadas as estatísticas descritivas dos dados coletados. O artigo finaliza, apresentando os resultados obtidos e as conclusões.

\section{Materiais e Métodos}

O presente artigo usa como estratégia metodológica o 'estudo de caso', que, segundo Yin (2001), possui uma vantagem distinta quando se faz uma questão do tipo 'como' ou 'por que' 
acerca de um conjunto contemporâneo de acontecimentos, a respeito dos quais o pesquisador tem pouco ou nenhum controle.

Para conhecer o processo estudado, foi realizado o mapeamento do fluxo das atividades envolvidas nas operações de setup de ferramentas, manutenção de ferramentas e reposição de matéria-prima, para cada um dos quatro componentes analisados neste trabalho. Conforme Rother e Shook (1999), com o mapeamento é possível visualizar e entender o fluxo do material e da informação, enquanto o produto segue o fluxo de valor.

Posteriormente, iniciou-se o dimensionamento do campo amostral. Para cada uma das atividades foram coletadas amostras preliminares, sendo calculada a média e o desvio padrão. Após, a partir do maior valor do desvio padrão encontrado, que foi 4,171 minutos, considerando um nível de significância igual a 5\% e aceitando 2 minutos de erro absoluto aceitável, o tamanho da amostra a ser coletada foi estimado, sendo de 30 dados por variável, por turno de trabalho analisado.

A partir da definição do número de amostras, foi realizado um diagnóstico para verificar o poder que o teste de variância teria, em termos de percepção de diferenças significativas entre as médias. A Figura 1 apresenta o resultado desta análise, utilizando um valor de $80 \%$ de poder, uma significância de 5\% e o tamanho de amostra igual a 30. Com base nesses parâmetros, o teste de variância detectar diferenças em pelo menos uma das médias, a partir de 0,5 desvios-padrão.

Figura 1 - Análise da Sensibilidade do Teste de Variância

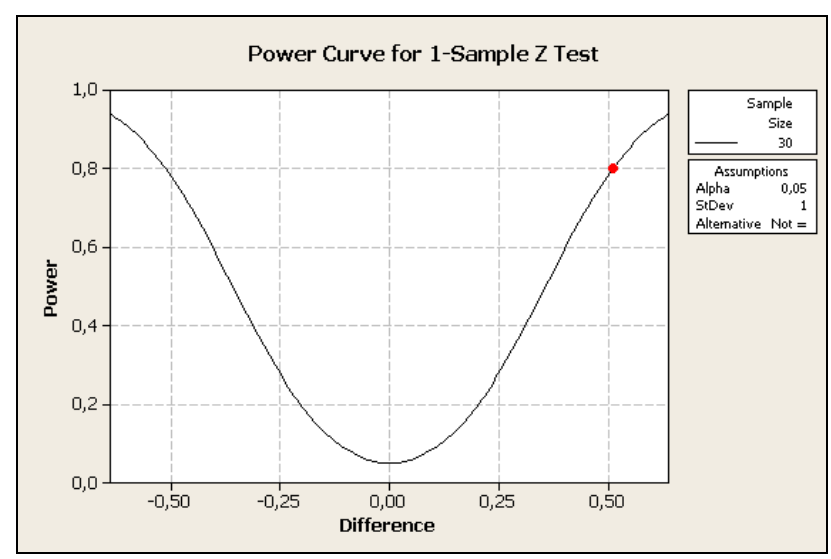

Fonte: Minitab versão 15 (2010)

Os dados coletados foram organizados no software Excel, para fins de tabulação e análises descritivas preliminares. Por fim, os dados foram exportados para o software SPSS, para realização de testes estatísticos de análise das operações, com o intuito de verificar as divergências nas médias foram realizados.

\section{Particularidades do Sistema Kanban de abastecimento}

Segundo Antunes et al (2008), o sistema Kanban pode ser entendido como uma 'ferramenta' de programação e controle da produção. Este método simplifica os sistemas os tradicionais de 
controle da produção (ordens de fabricação, montagem e compras) na medida em que, adotando um controle visual do material que circula na fábrica, elimina toda a circulação de papéis na estrutura de fabricação.

Entretanto, na fase preliminar de implantação do Kanban, é importante identificar a ocorrência de condições desfavoráveis ao uso desta técnica, das quais se citam (LAGE JUNIOR e GODINHO FILHO, 2006): (a) instabilidade dos tempos de processamento; (b) não padronização das operações; (c) demanda instável: e (d) incertezas no abastecimento de matérias-primas. Além destas questões, o impacto causado pelos parâmetros do sistema, utilizado para determinar o número de Kanbans, tais como: tempos do processo, variabilidade da demanda, taxas de chegada e saídas de peças, entre outros, não são apresentados de forma que clara, na literatura deste tema, que também ilustra modelos determinísticos para o dimensionamento, que diante das incertezas e da dinâmica de um sistema real se tornam inviáveis (KRISHNAMURTHY e SURI, 2006).

Com relação às incertezas (ocasionadas pela variação dos tempos ou falta de padronização) de um processo produtivo, o Kanban pode operar com pequenos níveis de estoque, quando as condições de variabilidade são baixas (SUWANRUJI e ENNS, 2006). Para Sanches et al (2007), são inúmeras as incertezas desconsideradas no dimensionamento determinístico de Kanbans, podendo-se causar situações não desejáveis no sistema. Conforme Antunes (1998) quanto maior a variabilidade do processo maior será a necessidade da utilização de estoques. Além do alto nível de estoque, a variabilidade pode causar filas, atrasos e aumentar o estoque em processo (BONVIK, GERSHWIN e TROXEL, 1995).

A partir dos relatos apresentados pelos autores e objetivando a redução dos níveis de estoques através do uso do Kanban, é necessário combater a variabilidade do processo produtivo ou então utilizar modelos de cálculo que consideram essa temática, os quais podem se tornar difíceis de serem aplicados em sistemas produtivos complexos.

\section{Análises Univariada e Multivariada de Variância (ANOVA/MANOVA)}

Para Bisquerra Alzina, Sarriera e Martinez (2004), a análise univariada (ANOVA) é uma generalização da prova $t$ de student e formulada por R.A Fischer. Conforme Hair et al (2009) a análise multivariada de variância (MANOVA) foi introduzida a várias décadas atrás pela formulação original de Wilks, sendo uma extensão da análise univariada (ANOVA) que tem como finalidade o uso de mais do que duas variáveis dependentes. A MANOVA mede as diferenças para duas ou mais variáveis dependentes métricas, com base em um conjunto de variáveis categóricas (não-métricas) que atuam como variáveis independentes. A hipótese nula do teste afirma que as amostras surgem de populações com médias iguais para uma variável dependente (ANOVA) ou um 
conjunto de variáveis dependentes (MANOVA). Essa hipótese pode ser aceita ou rejeitada, dependendo dos resultados de um teste de significância estatística.

Para se aplicar os testes ANOVA e MANOVA, os dados coletados devem atender a uma série de pressupostos, os quais, segundo Hair et al (2009), são: (i) exigências no tamanho da amostra - geral e por grupo: o tamanho de amostra deve superar as referências específicas em cada célula (grupo) com um mínimo recomendado de 20 observações; (ii) independência: as observações devem ser independentes; (iii) igualdade de matrizes de variância-covariância: outra suposição do teste MANOVA é a equivalência de matrizes de covariância nos grupos. Aqui, analisam-se as diferenças substanciais no montante de variância de um grupo versus outro grupo para as mesmas variáveis. O teste para verificar a igualdade de matrizes de covariância é o teste $M$ de Box, que fornece níveis de significância como resposta; (iv) normalidade: a suposição é que todas as variáveis sejam normais multivariadas. Violar essa suposição inicialmente cria problemas na aplicação do teste M de Box; e (v) linearidade e multicolinearidade entre as variáveis dependentes. Ainda, segundo Hair et al (2009), os procedimentos de teste univariado (ANOVA) são válidos somente quando a variável dependente é normalmente distribuída e que as variâncias são iguais para todos os grupos de tratamento.

Os resultados fornecidos com os testes ANOVA e MANOVA são mostrados através da comparação com o nível de significância. Se o valor de significância obtido no teste é maior que o valor de nível de significância admitido (corte) é possivel afirmar que os valores médios são semelhantes, não existindo diferenças significativas entre as médias observadas, o que valida à hipótese nula. Contudo ao obter um valor de significância do teste menor que o valor estipulado para corte, afirma-se que as médias são diferentes e rejeita-se a hipótese nula e se valida à hipótese alternativa que promove a existência de diferenças significativas entre as amostras.

Segundo Hair et al (2009), o teste MANOVA apresenta diferentes critérios para avaliar diferenças multivariadas ao longo de grupos. Os quatro mais conhecidos são: (i) o gcr de Roy; (ii) lambda de Wilks - também conhecido como a estatística $U$; (iii) traço de Hotelling; e (iv) critério de Pillai, onde, esses critérios avaliam as diferenças em 'dimensões' das variáveis dependentes.

A métrica de Roy é mais adequada quando as variáveis dependentes estão fortemente interrelacionadas sobre uma única dimensão, mas também é a medida mais facilmente afetada por violações das suposições. A métrica de lambda de Wilks considera todas as raízes características, ou seja, examina se os grupos são diferentes de algum modo, sem se preocupar com a possibilidade ocorrer diferenças em pelo menos uma combinação linear de variáveis dependentes. Outras medidas amplamente empregadas incluem o critério de Pillai e o traço de Hotelling, ambas semelhantes ao lambda de Wilks e podem ser aproximados através de uma estatística $F$. No entanto, se todas as 
suposições são atendidas e que as medidas dependentes são representativas de uma única dimensão de efeitos, então o gcr de Roy é o teste estatístico mais poderoso (HAIR et al, 2009).

\subsection{Teste Kruskal-Wallis}

Segundo Siegel (1975), o teste Kruskal-Wallis é um teste útil para decidir se $k$ amostras independentes provêm de populações diferentes. Para Bisquerra Alzina, Sarriera e Martinez (2004) este teste pode ser utilizado para decidir se, para $k$ amostras independentes, ocorre diferença entre suas médias.

Os valores amostrais quase que invariavelmente diferem entre si e o problema é decidir se essas diferenças entre as amostras significam diferenças efetivas entre as populações, ou se representam apenas variações casuais, que podem ser esperadas entre amostras aleatórias de uma mesma população. Essa técnica utiliza a hipótese nula de que $k$ amostras provenham da mesma população ou de populações idênticas com relação média, sendo que o pressuposto central é de que a variável em estudo tenha distribuição inerente continua (SIEGEL, 1975).

\section{Teste Kolmogorov-Smirnov}

O teste Kolmogorov-Smirnov, segundo Bisquerra Alzina, Sarriera e Martinez (2004) pode ser a prova mais adequada para comprovar se uma distribuição empírica se ajusta a um modelo normal. O teste procura especificar a distribuição de frequiência acumulada que ocorre sob a distribuição teórica e compará-la com a distribuição de freqüência acumulada observada. Determina-se o ponto em que essas duas distribuições (teórica e observada) acusam maior divergência (SIEGEL, 1975) e compara-se essa diferença com uma medida não paramétrica.

\section{Apresentação do Caso}

A empresa que fundamenta esta pesquisa é produtora de itens metálicos e plásticos, voltados ao mercado de utensílios domésticos, com aproximadamente 120 funcionários. O caso analisado refere-se ao setor de estampagem, o qual é denominado 'Linha 2'. O mix atual de produção é de 13 tipos de componentes. Os seguintes equipamentos estão dedicados à linha: uma prensa excêntrica de 65 toneladas, um alimentador eletrônico, um endireitador, um desbobinador, duas rosqueadeiras e uma furadeira: o desbobinador tem a função de suportar a bobina, e sua regulagem, evita que esta se desenrole por contra própria; o endireitador tem a finalidade de deixar a tira de aço mais uniforme, eliminando possíveis envergaduras; o alimentador eletrônico fornece o passo necessário que a tira de aço deve avançar em cada estágio da ferramenta; e prensa excêntrica fornece a força necessária para estampar o componente. A Figura 2 mostra o layout dos equipamentos na Linha 2. 
As ferramentas utilizadas para produzir os modelos de peças são do tipo 'progressivas', ou seja, com uma única ferramenta de diversos estágios, é possível obter o componente em seu estado final, sem a necessidade de utilizar outras ferramentas e máquinas, neste caso prensas, para o mesmo produto no processo de estampagem.

O horário de trabalho da 'Linha 2' é de dois turnos ininterruptos, de segunda à sexta, sendo que, em cada turno, há um operador responsável. A matéria-prima utilizada vem na forma de bobina, variando a largura e a espessura da tira. Um valor aproximado para o rendimento (em peças por bobina) é calculado por meio de um software específico, no qual são informados parâmetros do tipo: diâmetro externo e diâmetro interno da bobina, passo da ferramenta, espessura, entre outros.

Figura 2 - Layout da Linha 2

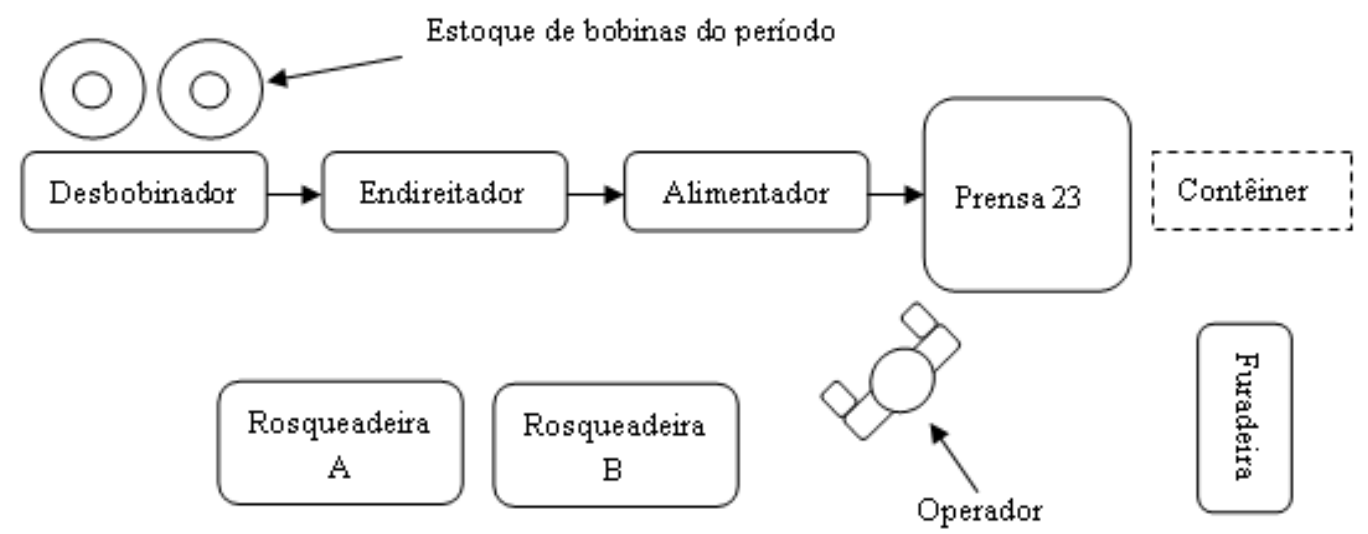

Fonte: Pesquisa de campo (2010)

A utilização do Kanban no contexto estudado foca no auxílio das atividades referentes à programação da produção na Linha 2. Esta prática seria iniciada com apenas 4 tipos de componentes, os quais apresentam maior demanda. O piloto prestar-se-ia a avaliar os benefícios de aplicabilidade da ferramenta e também treinar a equipe envolvida. O Kanban teria, entre outros aspectos, a finalidade de evitar o corte excessivo e também o corte parcial de bobina. Em caso de sucesso, não seria mais admitido o corte parcial da bobina, ou seja, uma vez iniciado o corte, esta seria totalmente processada. Na configuração vigente, há necessidade de remover a bobina processada pela metade no desbobinador e transportá-la até o estoque, gerando-se outros tipos de perdas ao processo.

\subsection{Setup de máquina, manutenção de ferramenta e abastecimento de matéria-prima}

Quando ocorre a necessidade de fazer a operação de setup de ferramenta, esta operação é dividida em duas frentes: a primeira diz respeito à substituição de ferramenta na máquina e a segunda refere-se à necessidade de abastecimento da matéria-prima (bobina) no desbobinador. Especificamente para a troca de ferramenta, as seguintes atividades são realizadas: (i) buscar o carro 
hidráulico; (ii) retirar a ferramenta da máquina e colocar no carro hidráulico; (iii) transportar a ferramenta até o setor de revisão e colocá-la sobre a bancada (neste ponto o ferramenteiro faz uma análise dos componentes principais e se necessário for, já é realizada a manutenção dos mesmos antes de guardá-la na estante); (iv) pegar a ferramenta do novo lote e transportar até a máquina; (v) trocar o curso, pois as ferramentas não possuem curso padronizado; (vi) levantar o fuso, colocar a ferramenta na mesa prensa e centrá-la; (vii) descer o fuso e fixar a ferramenta na prensa; (viii) aliviar o fuso; e (ix) ajustar altura do alimentador eletrônico e chamar o programa que gerencia o passe da tira para aquele tipo de produto.

Após colocar a ferramenta da nova ordem de produção na máquina, realiza-se o abastecimento do desbobinador. Quando ocorre a necessidade de abastecimento, este procedimento é feito da seguinte maneira: (i) o operador busca a garra no local onde ela é disposta, pois, existem também outros recursos que a utilizam; (ii) o operador leva a garra até o local onde são depositadas todas as bobinas e vai ao encontro da pilha onde está aquela que deve ser utilizada; (iii) a bobina é presa na garra e então levantada; (iv) a bobina é trazida até o desbobinador; (v) a bobina é colocada no desbobinador e fixada; e (vi) a tira é introduzida na ferramenta, passando pelo endireitador e pelo alimentador eletrônico. $\mathrm{O}$ abastecimento da bobina ocorre a todo o momento em que o processamento da bobina é totalmente finalizado, ou seja, ocorre também fora da operação setup. Para este caso, todas as atividades realizadas são iguais as relatadas anteriormente, quando esta operação é realizada em paralelo com a operação de setup.

Ao finalizar o abastecimento da bobina, são realizados os ajustes finais referentes à regulagem de altura do martelo e à regulagem do passo da tira. Em paralelo aos ajustes, o operador observa a existência de possíveis rebarbas nos furos e de marcas na superfície da peça. Também é necessária a realização de medições em cotas específicas, que varia conforme o tipo de peça. Depois de realizado os ajustes e as verificações, o contador de peças é zerado e inicia-se a produção. Cabe ressaltar que nenhuma outra operação é iniciada em paralelo, enquanto o operador esta realizando a operação setup, ou o abastecimento de bobina. Estas duas operações sempre têm prioridade na lista de trabalho do setor.

A manutenção de ferramenta refere-se somente à substituição dos componentes que podem vir a falhar durante o processo. Para cada tipo ferramenta, o setor de ferramentaria mantém um estoque de cada componente que mais apresenta problemas, a pronta substituição. As atividades envolvidas nesta operação são as seguintes: (i) buscar o carro hidráulico; (ii) retirar a ferramenta da máquina, colocando-a no carro hidráulico; (iii) transportar a ferramenta até o setor de revisão e colocá-la sobre a bancada; (iv) realizar a troca do componente danificado, realizado pelo ferramenteiro, que pode ser troca da bucha, de agulha, de faca ou de pino-guia; (v) transportar a ferramenta consertada até a máquina; (vi) colocar a ferramenta na mesa, centrar e fixar a ferramenta 
na prensa; e (vii) ligar a máquina e acompanhar o processo por alguns minutos para verificar se ocorre algum outro problema.

Quando a prensa está trabalhando normalmente, esta fornece um valor constante de ciclos por minuto. A eficiência da produção da máquina pode ser comprometida por três fatores: (a) quebra de algum componente da ferramenta - o que necessita retirar a ferramenta da máquina para substituí-lo, gastando tempo; (b) tempo de abastecimento da bobina - se o operador gastar muito tempo para repor a bobina, a máquina fica parada esperando a matéria-prima; e (c) tempo gasto com setup de ferramenta - quanto mais tempo o operador levar para colocar a máquina funcionar, maior será o tempo para concluir a ordem de produção.

\subsection{Aplicação da Análise de Variância nas operações pesquisadas}

A análise de pré-implantação do sistema Kanban é feita a partir dos valores temporais de cada uma das atividades pertencentes às operações descritas anteriormente. Nelas, é verificada a ocorrência de diferenças significativas entre as médias, através do uso da técnica de Análise de Variância, considerando os fatores (turno, produto e a interação turno*produto). Além desta técnica, será considerado como fator analítico, o coeficiente de variação (CV), pois para um conjunto de dados que apresenta alto grau de variabilidade e não apresentam diferenças significativas entre as médias deste grupo, é necessário buscar meios que proporcionem a redução deste coeficiente, evitando potenciais problemas no dimensionamento do Kanban.

Considerando as vertentes anteriormente relatadas, a aplicação dos testes ocorre da seguinte maneira: para os tempos de cada uma das atividades pertencentes à operação setup de ferramentas e abastecimento de bobina, será utilizado o teste ANOVA ou Kruskal-Wallis (dependendo da validação dos pressupostos), tendo o objetivo de detectar diferenças estatísticas, de forma univariada. Para operação de manutenção de ferramentas, deseja-se verificar de maneira multivariada, se os tempos das atividades envolvidas na manutenção de ferramentas, independente do componente a ser trocado, são estatisticamente diferentes ou faltam evidências que confirmem diferenças significativas em pelo menos uma das médias, logo, será aplicado o teste MANOVA.

A partir do grau obtido no coeficiente de variação e dos resultados fornecidos pela Análise de Variância, é verificada a necessidade de empregar técnicas oriundas do STP, como Troca Rápida de Ferramentas (TRF) e Padronização das atividades, objetivando a redução da variabilidade do processo, antes de implantar o sistema Kanban. Na Figura 3 são ilustradas as ações recomendadas para cada um dos três possíveis resultados obtidos. 
Figura 3 - Ações indicadas conforme o resultado obtido

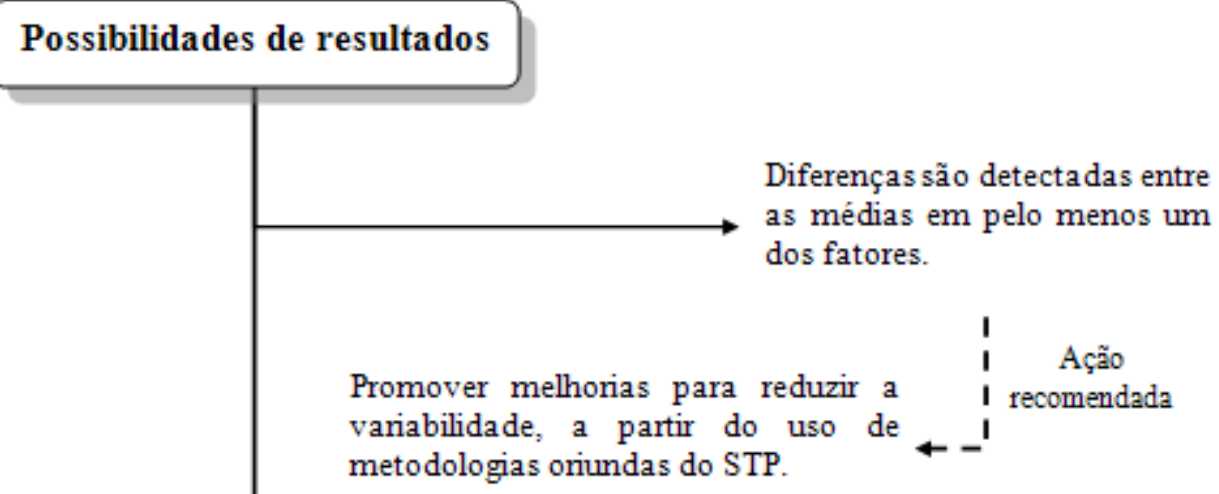

Faltam evidências que confirmem a existência de diferenças significativas e o CV obtido é superior a $30 \%$.

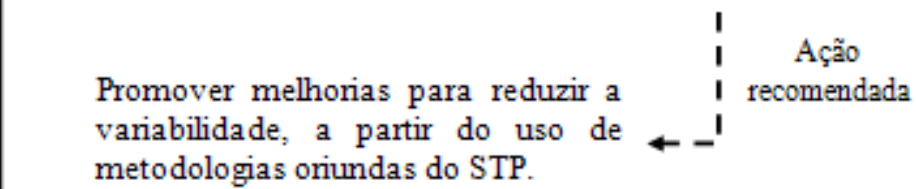

Faltam evidências que confirmem a existência de diferenças significativas e - CV obtido é inferior a $30 \%$.

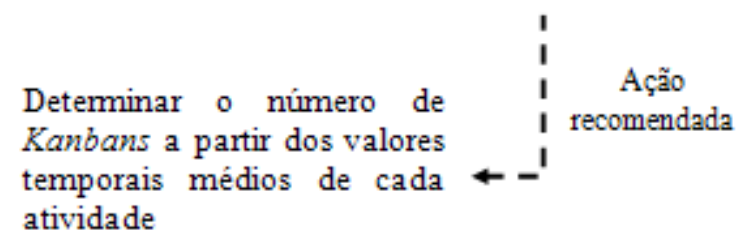

Fonte: Autoria própria (2010)

No que tange à sensibilidade do teste de variância, algumas considerações são apresentadas no Quadro 1, abordando as três possibilidades de resultados consideradas neste estudo. 
Quadro 1 - Erros na aceitação e rejeição da hipótese nula para o Teste de Variância

\begin{tabular}{|c|c|c|}
\hline \multirow[b]{2}{*}{$\begin{array}{l}\text { Real situação } \\
\text { no campo } \\
\text { amostral }\end{array}$} & \multicolumn{2}{|c|}{ Resultado obtido no Teste de Variância } \\
\hline & $\begin{array}{l}\text { O teste não detecta diferenças } \\
\text { maiores que } 0,5 \mathrm{dp} \text {. } \\
\text { (Não rejeita } \mathbf{H}_{0} \text { ) }\end{array}$ & $\begin{array}{l}\text { O teste detecta diferenças maiores } \\
\text { que } 0,5 \mathrm{dp} \\
\text { (Rejeita } \mathbf{H}_{\mathbf{0}} \text { ) }\end{array}$ \\
\hline $\begin{array}{l}\text { Não há } \\
\text { diferenças } \\
\text { maiores que } \\
0,5 \mathrm{dp}\end{array}$ & $\begin{array}{l}\text { Confiança de tomar a decisão } \\
\text { correta }(1-\alpha) \text { é } 95 \% \text {. } \\
\text { As possibilidades } 2 \text { e } 3 \text { representam } \\
\text { (Ho). Quando o teste de variância } \\
\text { promover um resultado que } \\
\text { favoreça }\left(\mathrm{H}_{0}\right) \text {, a aceitação desta } \\
\text { hipótese é feita com } 95 \% \text { de } \\
\text { confiança na decisão correta. }\end{array}$ & $\begin{array}{l}\text { Probabilidade rejeitar } \mathrm{H}_{0} \text { quando } \\
\text { este é verdadeiro é }(\alpha) 5 \% \text {. } \\
\mathrm{Na} \text { possibilidade } 1 \text {, existe a } \\
\text { probabilidade de } 5 \% \text { das diferenças } \\
\text { detectadas não serem realmente } \\
\text { significantes, levando a rejeição de } \\
\left(\mathrm{H}_{0}\right) \text {. }\end{array}$ \\
\hline $\begin{array}{l}\text { Há diferenças } \\
\text { maiores que } \\
0,5 \mathrm{dp}\end{array}$ & $\begin{array}{l}\text { Erro Tipo II ( } \beta) \text { : Falhar na } \\
\text { aceitação é de } 20 \% \text {. } \\
\text { Cabe ressaltar que nas } \\
\text { possibilidades } 2 \text { e } 3 \text { ocorre uma } \\
\text { probabilidade de } 20 \% \text { de Erro Tipo } \\
\text { II, referente a aceitação de }\left(\mathrm{H}_{0}\right) \text {, } \\
\text { quando esta deveria ser rejeitada. }\end{array}$ & $\begin{array}{l}\mathrm{O} \text { teste formece um poder de } 80 \% \\
(1-\beta) \text { no que se refere em rejeitar } \\
\mathrm{H}_{0} \text { corretamente. } \\
\text { A aceitação da hipótese que } \\
\text { promove diferenças significativas } \\
\left(\mathrm{H}_{1}\right) \text {, sendo esta representada pela } \\
\text { possibilidade } 1 \text {, é feita com base } \\
\text { em um valor de } 80 \% \text { de Poder em } \\
\text { termos de percepção de diferenças } \\
\text { superiores a } 0,5 \text { dp. }\end{array}$ \\
\hline
\end{tabular}

$\left(\mathrm{H}_{0}\right)$ - Hipótese Nula $\quad\left(\mathrm{H}_{1}\right)$ - Hipótese Altemativa

dp - Desvio padrão

Fonte: Autoria própria (2010)

Conforme apresentado no Quadro 1, quando o resultado do teste de variância não detectar diferenças maiores que $0,5 \mathrm{dp}$ em pelo menos uma das médias, é possivel afirmar com $95 \%$ de confiança $(\alpha=5 \%)$ que a aceitação do resultado está correta (não rejeita $\mathrm{H}_{0}$ ), quando não há diferenças maiores que $0,5 \mathrm{dp}$ no campo amostral. No entanto, existe a probabilidade de $20 \%$ de realmente existirem diferenças significativas no campo amostral, não detectadas pelo teste (Erro Tipo II). Contudo, quando o teste detecta diferenças superiores a $0,5 \mathrm{dp}$, ocorre a probabilidade de $5 \%(\alpha)$ de rejeitar $\mathrm{H}_{0}$ quando a real situação do campo amostral promove a não ocorrência de valores maiores que 0,5 dp (Erro Tipo I) e por fim, quando o teste detecta diferenças maiores que $0,5 \mathrm{dp}$ é com base na probabilidade de $80 \%$ (1- $\beta$ ) que a rejeição de $\mathrm{H}_{0}$ está correta. É valido ressaltar que um teste de alta sensibilidade terá um valor de $\beta$ (Erro tipo II) menor.

\section{Estatísticas descritivas dos dados de entrada}

Nesta seção, são apresentadas as estatísticas descritivas de cada uma das atividades, pertencentes às operações analisadas neste estudo. Nas tabelas 1 a 4 são ilustradas as atividades que compõem a operação de setup de ferramentas e abastecimento de bobina, referentes aos quatro tipos de componentes estampados na Linha 2. 
Os cálculos das estatísticas descritivas, apresentados nas Tabelas 1 a 13, não fazem distinção por turno. $\mathrm{O}$ valor da média para a atividade de buscar o carro hidráulico do produto $\mathrm{P}_{1}$ é 0,818 minutos (Tabela 1) calculada com base nas informações coletadas nos dois turnos (60 amostras). Os valores apresentados nas tabelas estão na escala de tempo 'minutos' e a sigla 'CV' ilustradas nas tabelas, diz respeito à abreviatura da métrica Coeficiente de Variação.

Tabela 1 - Estatísticas descritivas referentes ao produto 1

\begin{tabular}{|c|c|c|c|c|c|c|c|}
\hline Item & Variáveis (atividades) & Média & $\begin{array}{l}\text { Desvio } \\
\text { Padrão }\end{array}$ & Min. & Mediana & Máx. & C.V \\
\hline 1 & Buscar o carro hidráulico & 0,818 & 0,342 & 0,320 & 0,770 & 1,390 & 0,418 \\
\hline 2 & $\begin{array}{l}\text { Tirar a ferramenta da } \\
\text { máquina e por no carro } \\
\text { hidráulico }\end{array}$ & 5,171 & 1,561 & 2,200 & 5,350 & 7,800 & 0,301 \\
\hline 3 & $\begin{array}{l}\text { Transporte da ferramenta até } \\
\text { o setor de revisão e colocá- } \\
\text { la em cima da bancada }\end{array}$ & 1,067 & 0,319 & 0,400 & 1,200 & 1,500 & 0,298 \\
\hline 4 & $\begin{array}{l}\text { Pegar a firramenta do novo } \\
\text { lo te e transportar até a } \\
\text { máquina }\end{array}$ & 1,156 & 0,298 & 0,700 & 1,150 & 1,70 & 0,257 \\
\hline 5 & Trocar o curso & 10,298 & 1,210 & 8,200 & 10,000 & 12,400 & 0,117 \\
\hline 6 & $\begin{array}{l}\text { Subir o fuso, colocar a } \\
\text { ferramenta na mesa prensa e } \\
\text { centrar }\end{array}$ & 1,991 & 0,409 & 1,200 & 2,000 & 2,700 & 0,205 \\
\hline 7 & $\begin{array}{l}\text { Descer fuso e fixar a } \\
\text { ferramenta na prensa }\end{array}$ & 5,186 & 0,552 & 4,100 & 5,270 & 6,250 & 0,106 \\
\hline 8 & Aliviar o fuso & 0,451 & 0,198 & 0,100 & 0,500 & 0,800 & 0,439 \\
\hline 9 & $\begin{array}{l}\text { Ajustar a altura do } \\
\text { alimentador eletrônico } \\
\text { chamar o programa que } \\
\text { gerencia o passe da tira para } \\
\text { aquele tipo de produto }\end{array}$ & 1,092 & 0,365 & 0,600 & 1,000 & 1,700 & 0,334 \\
\hline 10 & $\begin{array}{l}\text { Abastecimento de bobina } \\
\text { (representa todas as } \\
\text { atividades envolvidas nesta } \\
\text { operação) }\end{array}$ & 10,287 & 1,089 & 8,600 & 10,250 & 12,000 & 0,105 \\
\hline 11 & Ajustes finais & 19,720 & 1,506 & 17,000 & 19,500 & 23,000 & 0,076 \\
\hline 12 & $\begin{array}{l}\text { Tempo Total gasto para } \\
\text { trocar Ferramenta }\end{array}$ & 57,248 & 2,664 & 51,500 & 57,350 & 63,00 & 0,046 \\
\hline
\end{tabular}

Fonte: Pesquisa de campo (2010) 
Tabela 2 - Estatísticas Descritivas referentes ao produto 2

\begin{tabular}{c|l|c|c|c|c|c|c}
\hline Item & \multicolumn{1}{|c|}{ Variáveis (atividades) } & Média & $\begin{array}{l}\text { Desvio } \\
\text { Padrão }\end{array}$ & Min. & Mediana & Máx. & C.V \\
\hline 1 & Buscar o carro hidráulico & 0,825 & 0,324 & 0,330 & 0,810 & 1,380 & 0,392 \\
\hline 2 & $\begin{array}{l}\text { Tirar a ferramenta da } \\
\text { máquina e por no carro } \\
\text { hidráulico }\end{array}$ & 5,753 & 1,702 & 2,200 & 5,580 & 7,900 & 0,295 \\
\hline 3 & $\begin{array}{l}\text { Transporte da ferramenta até } \\
\text { o setor de revisão e colocá- } \\
\text { laem cima da bancada }\end{array}$ & 1,025 & 0,301 & 0,400 & 1,100 & 1,500 & 0,293 \\
\hline 4 & $\begin{array}{l}\text { Pegar a ferramenta do novo } \\
\text { lote e transportar até a } \\
\text { máquina }\end{array}$ & 1,221 & 0,268 & 0,800 & 1,300 & 1,700 & 0,219 \\
\hline 5 & Trocar o curso & 10,220 & 1,211 & 8,200 & 10,200 & 12,400 & 0,118 \\
\hline 6 & $\begin{array}{l}\text { Subiro fuso, colocar a } \\
\text { ferramenta na mesa prensa e } \\
\text { centrar }\end{array}$ & 1,920 & 0,441 & 1,200 & 1,900 & 2,700 & 0,229 \\
\hline 7 & $\begin{array}{l}\text { Descer fuso e fixar a } \\
\text { ferramenta na prensa }\end{array}$ & 5,151 & 0,575 & 4,180 & 5,100 & 6,190 & 0,111 \\
\hline 8 & Aliviar o fuso & 0,4483 & 0,219 & 0,100 & 0,400 & 0,800 & 0,488 \\
\hline 12 & $\begin{array}{l}\text { Ajustar a altura do } \\
\text { alimentador eletrônico e } \\
\text { chamar o pro grama que } \\
\text { gerencia o passe da tira para } \\
\text { aquele tipo de produto }\end{array}$ & 1,180 & 0,351 & 0,500 & 1,200 & 1,700 & 0,297 \\
\hline 11 & $\begin{array}{l}\text { Abastecimento de bobina } \\
\text { (representa todas as } \\
\text { atividades envolvidas nesta } \\
\text { operação) }\end{array}$ & 10,453 & 1,043 & 8,700 & 10,350 & 12,000 & 0,099 \\
\hline trocar Ferrames finais & 29,563 & 3,020 & 22,700 & 29,700 & 36,600 & 0,102 \\
\hline
\end{tabular}

Fonte: Pesquisa de campo (2010) 
Tabela 3 - Estatísticas Descritivas referentes ao produto 3

\begin{tabular}{|c|c|c|c|c|c|c|c|}
\hline Item & Variáve is (atividades) & Média & $\begin{array}{l}\text { Desvio } \\
\text { Padrão }\end{array}$ & Min. & Mediana & Máx. & C.V \\
\hline 1 & Buscar o carro hidráulico & 0,918 & 0,300 & 0,330 & 0,940 & 1,400 & 0,355 \\
\hline 2 & $\begin{array}{l}\text { Tirar a ferramenta da } \\
\text { máquina e por no carro } \\
\text { hidráulico }\end{array}$ & 4,840 & 1,647 & 2,100 & 4,600 & 7,900 & 0,340 \\
\hline 3 & $\begin{array}{l}\text { Transporte da ferramenta até } \\
\text { o setor de revisão e colocá- } \\
\text { la em cima da bancada }\end{array}$ & 0,934 & 0,303 & 0,400 & 0,900 & 1,400 & 0,324 \\
\hline 4 & $\begin{array}{l}\text { Pegar a ferramenta do novo } \\
\text { lo te e transportar até a } \\
\text { máquina }\end{array}$ & 1,195 & 0,278 & 0,700 & 1,150 & 1,700 & 0,232 \\
\hline 5 & Tro car o curso & 10,358 & 1,201 & 8,200 & 10,400 & 12,600 & 0,115 \\
\hline 6 & $\begin{array}{l}\text { Subir o fuso, colocar a } \\
\text { ferramenta na mesa prensa e } \\
\text { centrar }\end{array}$ & 1,930 & 0,437 & 1,300 & 1,900 & 2,700 & 0,226 \\
\hline 7 & $\begin{array}{l}\text { Descer fuso e fixar a } \\
\text { ferramenta na prensa }\end{array}$ & 5,080 & 0,634 & 4,120 & 4,905 & 6,190 & 0,124 \\
\hline 8 & Aliviar o fuso & 0,483 & 0,219 & 0,100 & 0,500 & 0,800 & 0,453 \\
\hline 9 & $\begin{array}{l}\text { Ajustar a altura do } \\
\text { alimentador eletrônico e } \\
\text { chamar o programa que } \\
\text { gerencia o passe da tira para } \\
\text { aquele tipo de produto }\end{array}$ & 1,151 & 0,358 & 0,500 & 1,150 & 1,700 & 0,311 \\
\hline 10 & $\begin{array}{l}\text { Abastecimento de bobina } \\
\text { (representa todas as } \\
\text { atividades envolvidas nesta } \\
\text { operação) }\end{array}$ & 10,390 & 0,979 & 8,600 & 10,500 & 12,100 & 0,094 \\
\hline 11 & Ajustes finais & 15,313 & 1,970 & 12,000 & 15,400 & 20,000 & 0,128 \\
\hline 12 & $\begin{array}{l}\text { Tempo Total gasto para } \\
\text { trocar Ferramenta }\end{array}$ & 52,593 & 3,745 & 44,900 & 52,55 & 62,300 & 0,071 \\
\hline
\end{tabular}

Fonte: Pesquisa de campo (2010) 
Tabela 4 - Estatísticas Descritivas referentes ao produto 4

\begin{tabular}{|c|c|c|c|c|c|c|c|}
\hline Item & Variáveis (atividades) & Média & $\begin{array}{l}\text { Desvio } \\
\text { Padrão }\end{array}$ & Min. & Mediana & Máx. & C.V \\
\hline 1 & Buscar o carro hidráulico & 0,862 & 0,316 & 0,310 & 0,830 & 1,400 & 0,367 \\
\hline 2 & $\begin{array}{l}\text { Tirar a ferramenta da } \\
\text { máquina e por no carro } \\
\text { hidráulico }\end{array}$ & 4,925 & 1,693 & 2,100 & 4,900 & 7,900 & 0,344 \\
\hline 3 & $\begin{array}{l}\text { Transporte da ferramenta até } \\
\text { o setor de revisão e colocá- } \\
\text { la em cima da bancada }\end{array}$ & 0,870 & 0,328 & 0,400 & 0,800 & 1,400 & 0,377 \\
\hline 4 & $\begin{array}{l}\text { Pegar a frramenta do novo } \\
\text { lo te e transportar até a } \\
\text { máquina }\end{array}$ & 1,158 & 0,264 & 0,700 & 1,100 & 1,700 & 0,228 \\
\hline 5 & Tro car o curso & 10,456 & 1,305 & 8,300 & 10,500 & 12,500 & 0,125 \\
\hline 6 & $\begin{array}{l}\text { Subir o fuso, colocar a } \\
\text { ferramenta na mesa prensa e } \\
\text { centrar }\end{array}$ & 1,988 & 0,419 & 1,200 & 1,950 & 2,700 & 0,211 \\
\hline 7 & $\begin{array}{l}\text { Descer fuso e fixar a } \\
\text { ferramenta na prensa }\end{array}$ & 5,122 & 0,590 & 4,130 & 5,055 & 6,160 & 0,115 \\
\hline 8 & Aliviar o fuso & 0,4300 & 0,233 & 0,100 & 0,400 & 0,800 & 0,542 \\
\hline 9 & $\begin{array}{l}\text { Ajustar a altura do } \\
\text { alimentador eletrônico e } \\
\text { chamar o programa que } \\
\text { gerencia o passe da tira para } \\
\text { aquele tipo de produto }\end{array}$ & 1,145 & 0,354 & 0,500 & 1,100 & 1,700 & 0,309 \\
\hline 10 & $\begin{array}{l}\text { Abastecimento de bobina } \\
\text { (representa todas as } \\
\text { atividades envolvidas nesta } \\
\text { operação) }\end{array}$ & 10,375 & 0,990 & 8,600 & 10,600 & 12,100 & 0,095 \\
\hline 11 & Ajustes finais & 27,415 & 0,888 & 26,000 & 27,400 & 28,900 & 0,032 \\
\hline 12 & $\begin{array}{l}\text { Tempo Total gasto para } \\
\text { trocar Ferramenta }\end{array}$ & 64,753 & 2,190 & 60,800 & 64,700 & 71,800 & 0,034 \\
\hline
\end{tabular}

Fonte: Pesquisa de campo (2010)

$\mathrm{Na}$ operação de manutenção de ferramentas, cabe ressaltar que algumas das atividades realizadas nesta operação são iguais às ocorridas na operação setup. O Quadro 2 ilustra as atividades envolvidas na operação de manutenção de ferramentas e também, quais atividades são similares entre as duas operações. 
Quadro 2 - Atividades similares que ocorrem entre as duas operações

\begin{tabular}{|c|c|c|}
\hline Item & $\begin{array}{c}\text { Atividades envolvidas na operação de } \\
\text { manutenção de ferramentas }\end{array}$ & Operação setup de ferramentas \\
\hline 1 & Buscar o carro hidráulico & Iguais nas duas operações \\
\hline 2 & $\begin{array}{l}\text { Tirar a ferramenta da máquina e por no carro } \\
\text { hidráulico }\end{array}$ & Iguais nas duas operações \\
\hline 3 & $\begin{array}{l}\text { Transporte da ferramenta até o setor de } \\
\text { revisão e colocá-la em cima da bancada }\end{array}$ & Iguais nas duas operações \\
\hline 4 & Troca do componente danificado & Não ocorre nesta operação \\
\hline 5 & $\begin{array}{l}\text { Transporte da ferramenta já consertada até a } \\
\text { máquina }\end{array}$ & $\begin{array}{l}\text { Pegar a ferramenta do novo lote e } \\
\text { transportar até a máquina }\end{array}$ \\
\hline 6 & $\begin{array}{l}\text { Colocar a ferramenta na mesa, centrar e fixar } \\
\text { a ferramenta na prensa }\end{array}$ & $\begin{array}{l}\text { Ocorre de forma similar, no } \\
\text { entanto, serão utilizados dados } \\
\text { específicos desta atividade para a } \\
\text { análise. }\end{array}$ \\
\hline
\end{tabular}

Fonte: Pesquisa de campo (2010)

As Tabelas 5 a 8 ilustram os valores de tempo gasto para trocar os componentes internos da ferramenta para cada componente estampado.

Tabela 5 - Estatísticas Descritivas referentes ao produto 1

\begin{tabular}{l|c|c|c|c}
\hline Variáveis (atividades) & Troca da bucha & $\begin{array}{c}\text { Troca de } \\
\text { agulha }\end{array}$ & $\begin{array}{c}\text { Troca da } \\
\text { faca }\end{array}$ & $\begin{array}{c}\text { Troca de pino- } \\
\text { guia }\end{array}$ \\
\hline Média & 9,834 & 5,064 & 7,173 & 6,830 \\
\hline Desvio Padrão & 2,929 & 1,247 & 1,530 & 1,250 \\
\hline Mínimo & 4,200 & 3,210 & 4,300 & 4,630 \\
\hline Mediana & 9,570 & 4,880 & 6,960 & 6,940 \\
\hline Máximo & 14,970 & 10,300 & 11,600 & 8,960 \\
\hline Coeficiente de variação & 0,297 & 0,246 & 0,213 & 0,183 \\
\hline
\end{tabular}

Fonte: Pesquisa de campo (2010)

Tabela 6 - Estatísticas Descritivas referentes ao produto 2

\begin{tabular}{l|c|c|c|c}
\hline Variáveis (atividades) & Troca da bucha & $\begin{array}{c}\text { Troca de } \\
\text { agulha }\end{array}$ & $\begin{array}{c}\text { Troca da } \\
\text { faca }\end{array}$ & $\begin{array}{l}\text { Troca de pino- } \\
\text { guia }\end{array}$ \\
\hline Média & 9,832 & 5,259 & 7,479 & 6,932 \\
\hline Desvio Padrão & 2,760 & 1,111 & 1,601 & 1,348 \\
\hline Mínimo & 5,040 & 3,210 & 5,040 & 4,590 \\
\hline Mediana & 9,675 & 5,270 & 7,680 & 6,850 \\
\hline Máximo & 14,060 & 7,130 & 11,000 & 12,000 \\
\hline Coeficiente de variação & 0,281 & 0,211 & 0,214 & 0,194 \\
\hline
\end{tabular}

Fonte: Pesquisa de campo (2010) 
Tabela 7 - Estatísticas Descritivas referentes ao produto 3

\begin{tabular}{l|c|c|c|c}
\hline Variáveis (atividades) & Troca dabucha & $\begin{array}{c}\text { Troca de } \\
\text { agulha }\end{array}$ & $\begin{array}{c}\text { Troca da } \\
\text { faca }\end{array}$ & $\begin{array}{l}\text { Troca de pino- } \\
\text { guia }\end{array}$ \\
\hline Média & 10,119 & 5,391 & 7,441 & 6,805 \\
\hline Desvio Padrão & 2,831 & 1,112 & 1,538 & 1,355 \\
\hline Mínimo & 5,080 & 3,270 & 5,120 & 4,000 \\
\hline Mediana & 10,075 & 5,405 & 7,440 & 6,850 \\
\hline Máximo & 14,970 & 7,250 & 10,140 & 8,980 \\
\hline Coeficiente de variação & 0,280 & 0,206 & 0,207 & 0,199 \\
\hline
\end{tabular}

Fonte: Pesquisa de campo (2010)

Tabela 8 - Estatísticas Descritivas referentes ao produto 4

\begin{tabular}{l|c|c|c|c}
\hline Variáveis (atividades) & Troca da bucha & $\begin{array}{c}\text { Troca de } \\
\text { agulha }\end{array}$ & $\begin{array}{c}\text { Troca da } \\
\text { faca }\end{array}$ & $\begin{array}{l}\text { Troca de pino- } \\
\text { guia }\end{array}$ \\
\hline Média & 10,395 & 5,290 & 7,788 & 6,457 \\
\hline Desvio Padrão & 2,869 & 1,204 & 1,535 & 1,363 \\
\hline Mínimo & 5,190 & 3,200 & 5,020 & 4,000 \\
\hline Mediana & 10,760 & 5,375 & 7,890 & 6,385 \\
\hline Máximo & 14,990 & 7,200 & 10,060 & 8,970 \\
\hline Coeficiente de variação & 0,276 & 0,228 & 0,197 & 0,211 \\
\hline
\end{tabular}

Fonte: Pesquisa de campo (2010)

Na Tabela 9 são apresentadas as estatísticas da atividade de colocar a ferramenta na mesa, centrar e fixar a ferramenta na prensa para cada produto. Essa atividade é realizada após a troca do componente danificado.

Tabela 9 - Estatísticas Descritivas

\begin{tabular}{l|c|c|c|c}
\hline Variáveis (atividades) & Produto 1 & Produto 2 & Produto 3 & Produto 4 \\
\hline Média & 5,148 & 5,234 & 5,034 & 5,036 \\
\hline Desvio Padrão & 1,700 & 1,642 & 1,757 & 1,466 \\
\hline Mínimo & 2,400 & 2,400 & 2,300 & 2,400 \\
\hline Mediana & 4,650 & 5,150 & 4,800 & 5,000 \\
\hline Máximo & 8,100 & 8,000 & 9,600 & 8,000 \\
\hline Coeficiente de variação & 0,330 & 0,314 & 0,349 & 0,291 \\
\hline
\end{tabular}

Fonte: Pesquisa de campo (2010)

As estatísticas dos dados referentes ao tempo total de manutenção de ferramentas (realizar todas as atividades necessárias para a troca de cada tipo de componente, as quais estão expressas no Quadro 2) são a seguir apresentadas nas Tabelas 10 a 13. 
Tabela 10 - Estatísticas Descritivas referentes ao produto 1

\begin{tabular}{l|c|c|c|c}
\hline Variáveis (atividades) & Troca da bucha & $\begin{array}{c}\text { Troca de } \\
\text { agulha }\end{array}$ & $\begin{array}{c}\text { Troca da } \\
\text { faca }\end{array}$ & $\begin{array}{l}\text { Troca de pino- } \\
\text { guia }\end{array}$ \\
\hline Média & 22,127 & 17,394 & 19,494 & 19,001 \\
\hline Desvio Padrão & 3,578 & 2,337 & 2,533 & 2,226 \\
\hline Mínimo & 14,280 & 11,750 & 13,520 & 13,010 \\
\hline Mediana & 21,785 & 17,265 & 19,520 & 19,915 \\
\hline Máximo & 30,110 & 23,46 & 24,900 & 24,930 \\
\hline Coeficiente de variação & 0,162 & 0,134 & 0,130 & 0,117 \\
\hline
\end{tabular}

Fonte: Pesquisa de campo (2010)

Tabela 11 - Estatísticas Descritivas referentes ao produto 2

\begin{tabular}{l|c|c|c|c}
\hline Variáveis (atividades) & Troca da bucha & $\begin{array}{c}\text { Troca de } \\
\text { agulha }\end{array}$ & $\begin{array}{c}\text { Troca da } \\
\text { faca }\end{array}$ & $\begin{array}{l}\text { Troca de pino- } \\
\text { guia }\end{array}$ \\
\hline Média & 22,702 & 18,203 & 20,323 & 20,022 \\
\hline Desvio Padrão & 3,623 & 2,496 & 2,924 & 2,532 \\
\hline Mínimo & 14,660 & 12,190 & 14,330 & 15,140 \\
\hline Mediana & 23,000 & 18,265 & 20,640 & 19,900 \\
\hline Máximo & 29,450 & 23,330 & 25,840 & 26,240 \\
\hline Coeficiente de variação & 0,160 & 0,137 & 0,144 & 0,126 \\
\hline
\end{tabular}

Fonte: Pesquisa de campo (2010)

Tabela 12 - Estatísticas Descritivas referentes ao produto 3

\begin{tabular}{l|c|c|c|c}
\hline Variáveis (atividades) & Troca da bucha & $\begin{array}{c}\text { Troca de } \\
\text { agulha }\end{array}$ & $\begin{array}{c}\text { Troca da } \\
\text { faca }\end{array}$ & $\begin{array}{l}\text { Troca de pino- } \\
\text { guia }\end{array}$ \\
\hline Média & 21,528 & 16,909 & 19,123 & 18,428 \\
\hline Desvio Padrão & 3,398 & 2,567 & 2,729 & 2,788 \\
\hline Mínimo & 14,850 & 11,300 & 12,790 & 12,500 \\
\hline Mediana & 21,510 & 17,000 & 19,070 & 18,420 \\
\hline Máximo & 28,850 & 22,430 & 24,680 & 24,030 \\
\hline Coeficiente de variação & 0,158 & 0,152 & 0,143 & 0,151 \\
\hline
\end{tabular}

Fonte: Pesquisa de campo (2010)

Tabela 13 - Estatísticas Descritivas referentes ao produto 4

\begin{tabular}{l|c|c|c|c}
\hline Variáveis (atividades) & Troca da bucha & $\begin{array}{c}\text { Troca de } \\
\text { agulha }\end{array}$ & $\begin{array}{c}\text { Troca da } \\
\text { faca }\end{array}$ & $\begin{array}{l}\text { Troca de pino- } \\
\text { guia }\end{array}$ \\
\hline Média & 21,95 & 17,198 & 19,862 & 18,321 \\
\hline Desvio Padrão & 4,171 & 2,607 & 2,9168 & 2,842 \\
\hline Mínimo & 11,550 & 10,650 & 13,870 & 11,210 \\
\hline Mediana & 22,085 & 17,550 & 19,865 & 18,710 \\
\hline Máximo & 29,170 & 21,950 & 26,080 & 23,430 \\
\hline Coeficiente de variação & 0,190 & 0,152 & 0,147 & 0,155 \\
\hline
\end{tabular}

Fonte: Pesquisa de campo (2010) 


\section{Resultados do Teste de Variância}

Inicia-se a análise de resultados a partir das informações referentes ao setup de ferramentas e abastecimento de bobinas. Nas variáveis onde o padrão normal não foi atendido, que são: (a) transporte da ferramenta até o setor de revisão e colocá-la em cima da bancada ( $p=0,001)$; (b) pegar a ferramenta do novo lote e transportar até a máquina $(p=0,000)$; (c) subir o fuso, colocar a ferramenta na mesa prensa e centrar ( $p=0,041)$; (d) aliviar o fuso $(p=0,000)$; (e) ajustar a altura do alimentador eletrônico e chamar o programa que gerencia o passe da tira para aquele tipo de produto ( $p=0,005)$; e (f) ajuste finais $(p=0,000)$, foi aplicado o teste Kruskal-Wallis. No restante das variáveis onde o padrão normal foi atendido, foi aplicado o teste ANOVA.

Ao realizar o teste ANOVA, o software SPSS versão 17, oferece a possibilidade de analisar se as variâncias dos dados pertencentes às variáveis são homogêneas, através do teste de Levene. Ao obter um nível de significância do teste maior que o nível de significância admitido (corte), não se rejeita a hipótese que promove homogeneidade das variâncias (igualdade das variâncias). Os resultados obtidos no teste de Levene são apresentados na Tabela 14. É validada a hipótese que promove a homogeneidade nas variâncias, para os resultados maiores que 5\%. É visto, no entanto, que na interação turno*produto da variável descer fuso e fixar a ferramenta na prensa, o teste afirma a não ocorrência de igualdade de variâncias, não atendendo o pré-requisito para a realização do teste ANOVA. 
Tabela 14 - Resultados o teste de Levene

\begin{tabular}{|c|c|c|c|c|}
\hline Item & Va niáveis (ativida des) & Turno $(p)$ & Produto $(p)$ & Turno * Produto $(p)$ \\
\hline 1 & Buscar o carro hidráulico & 0,652 & 0,492 & 0,282 \\
\hline 2 & $\begin{array}{l}\text { Tirar a ferramenta da máquina } \\
\text { e por no carro hidráulico }\end{array}$ & 0,099 & 0,553 & 0,674 \\
\hline 3 & $\begin{array}{l}\text { Transporte da ferramenta até o } \\
\text { setor de revisão e co locá-la em } \\
\text { cima da bancada }\end{array}$ & - & - & - \\
\hline 4 & $\begin{array}{l}\text { Pegar a ferramenta do novo lo te } \\
\text { e transportar até a máquina }(a)\end{array}$ & - & - & - \\
\hline 5 & Tro car o curso & 0,640 & 0,746 & 0,093 \\
\hline 6 & $\begin{array}{l}\text { Subir o fuso, colocar a } \\
\text { ferramenta na mesa prensa e } \\
\text { centrar }\end{array}$ & - & - & - \\
\hline 7 & $\begin{array}{l}\text { Descer fuso e fixar a } \\
\text { ferramenta na prensa }\end{array}$ & 0,287 & 0,176 & 0,014 \\
\hline 8 & Aliviar o fuso & - & - & - \\
\hline 9 & $\begin{array}{l}\text { Ajustar a altura do alimentador } \\
\text { eletrônico e chamar o programa } \\
\text { que gerencia o passe da tira }(a)\end{array}$ & - & - & - \\
\hline 10 & $\begin{array}{l}\text { Abastecimento de bobina } \\
\text { (representa todas as atividades } \\
\text { envolvidas ne sta operação) }\end{array}$ & 0,589 & 0,407 & 0,612 \\
\hline 11 & Ajustes finais & - & - & - \\
\hline 12 & $\begin{array}{l}\text { Tempo To tal gas to para trocar } \\
\text { Ferramenta }\end{array}$ & 0,005 & 0,000 & 0,015 \\
\hline
\end{tabular}

$p$ - significância estimada.

(a) - os dados coletados não seguem um padrão normal de distribuição, portanto para estas variáveis foi utilizado o Teste Kruskal-Wallis.

Fonte: software SPSS versão 17 (2010)

As informações pertinentes ao resultado dos testes ANOVA e Kruskal-Wallis são apresentadas na Tabela 15. Para os valores de $(p)$ maiores que 5\%, o teste ANOVA mostra que não ocorre diferenças entre os valores de tempo para uma determinada atividade. Por exemplo, na atividade de buscar o carro hidráulico, a qual segue o padrão normal $(p=0,078)$, ao comparar os valores de tempo gasto nesta atividade ao longo do turno de trabalho, conclui-se que faltam evidências que promovem diferenças entre as médias $(p=0,403)$. O mesmo ocorre quando é comparado os valores desta atividade entre os quatro tipos de produtos estampados $(p=0,305) \mathrm{e}$ também, para a interação turno*produto $(p=0,930)$. Já na atividade que consiste em tirar a ferramenta da máquina e por no carro hidráulico que possui normalidade nos dados $(p=0,117)$, o teste ANOVA mostra que os valores temporais são significativamente diferentes para todos os fatores analisados. 
Tabela 15 - Resultados dos testes ANOVA e Kruskal-Wallis

\section{Setup de Ferramenta e Aba stecimento de bobina}

\begin{tabular}{|c|c|c|c|c|}
\hline Item & Va niáveis (ativida des) & Turno $(p)$ & Produto $(p)$ & Turno * Produto $(p)$ \\
\hline 1 & Buscar o carro hidráulico & 0,403 & 0,305 & 0,930 \\
\hline 2 & $\begin{array}{l}\text { Tirar a ferramenta da máquina } \\
\text { e por no carro hidráulico }\end{array}$ & 0,047 & 0,012 & 0,001 \\
\hline 3 & $\begin{array}{l}\text { Transporte da ferramenta até o } \\
\text { setor de revisão e colocá-la em } \\
\text { cima da bancada }\end{array}$ & 0,050 & 0,004 & - \\
\hline 4 & $\begin{array}{l}\text { Pegar a ferramenta do novo lote } \\
\text { e transportar até a máquina }(a)\end{array}$ & 0,039 & 0,516 & - \\
\hline 5 & Trocar o curso & 0,047 & 0,759 & 0,234 \\
\hline 6 & $\begin{array}{l}\text { Subir o fuso, colocar a } \\
\text { ferramenta na mesa prensa e } \\
\text { centrar } \quad(a)\end{array}$ & 0,776 & 0,662 & - \\
\hline 7 & $\begin{array}{l}\text { Descer fuso e fixar a } \\
\text { ferramenta na prensa }\end{array}$ & 0,048 & 0,790 & (b) \\
\hline 8 & Aliviar o fuso & 0,222 & 0,584 & - \\
\hline 9 & $\begin{array}{l}\text { Ajustar a altura do alimentador } \\
\text { eletrônico e chamar o pro grama } \\
\text { que gerencia o passe da tira }(a)\end{array}$ & 0,047 & 0,610 & - \\
\hline 10 & $\begin{array}{l}\text { Abastecimento de bobina } \\
\text { (repres enta todas as atividades } \\
\text { envolvidas nesta operação) }\end{array}$ & 0,867 & 0,850 & 0,196 \\
\hline 11 & Ayustes finais & 0,543 & 0,000 & - \\
\hline 12 & $\begin{array}{l}\text { Tempo Total gas to para trocar } \\
\text { Ferramenta }\end{array}$ & 0,487 & 0,000 & - \\
\hline
\end{tabular}

$p$ - significância estimada.

(a) - os dados coletados não seguem um padrão normal de distribuição, portanto para estas variáveis foi utilizado o Teste Kruskal-Wallis (KW).

(b) - o valor de significância do Teste de Levene é menor que 5\%, logo, foi aplicado o teste (KW).

Fonte: software SPSS versão 17 (2010)

Em seguida foram analisadas as informações referentes à operação de manutenção de ferramentas. Na variável colocar a ferramenta na mesa, centrar e fixar a ferramenta na prensa foi aplicado inicialmente o teste de Kolmogorov-Smirnov. O resultado obtido neste teste, afirma que os dados não seguem uma distribuição normal $(p=0,024)$. Diante dessa questão, utilizou-se o teste de Kruskal-Wallis, onde os valores de significância são apresentados na Tabela 16.

Tabela 16 - Atividade que ocorre somente na operação de manutenção de ferramentas

\begin{tabular}{l|c|c|c}
\hline \multicolumn{1}{c|}{ Variáveis (atividades) } & Turno $(p)$ & Produto $(p)$ & $\begin{array}{c}\text { Turno * Produto } \\
(p)\end{array}$ \\
\hline $\begin{array}{l}\text { Colocar a ferramenta namesa, centrar e } \\
\text { fixar a ferramentana prensa }\end{array}$ & 0,763 & 0,852 & - \\
\hline
\end{tabular}

$p$ - significância estimada.

Fonte: software SPSS versão 17 (2010) 
Com base nos índices apresentado na Tabela 16, onde $(p>0,05)$ é possível concluir que ocorre a falta de elementos que comprovem diferenças entre os valores temporais, em ambos fatores.

Nas variáveis referentes à substituição dos componentes internos da ferramenta, que são: troca da bucha, troca de agulha, troca da faca e troca de pino-guia, foi aplicado o teste MANOVA. Juntamente com este teste foi realizado o teste $\mathrm{M}$ de Box, que testa a homogeneidade univariada da variância, para cada uma das variáveis dependentes de forma individual. O valor de significância obtido foi $(p=0,477)$ o que valida a hipótese que indica aceite de igualdade de variância dos grupos.

Os valores de significância obtidos no teste MANOVA, são apresentados na Tabela 17, segundo o critério de Pillai, que é robusto em situações onde o tamanho da amostra diminui, ou se a homogeneidade de covariâncias é violada (HAIR et al, 2009).

Tabela 17 - Resultados do teste MANOVA

\begin{tabular}{|c|c|c|c|c|}
\hline \multicolumn{5}{|c|}{ Manutenção de Ferramenta (troca de componentes) } \\
\hline Item & Varíveis (ativida des) & Turno $(p)$ & Produto $(p)$ & Turno * Produto $(p)$ \\
\hline 1 & Troca dabucha & \multirow{4}{*}{0,286} & \multirow{4}{*}{0,141} & \multirow{4}{*}{0,031} \\
\hline 2 & Troca de agulha & & & \\
\hline 3 & Troca da faca & & & \\
\hline 4 & Troca de pino-guia & & & \\
\hline
\end{tabular}

É possível observar na Tabela 17 que ao comparar as variáveis referentes à troca dos componentes, considerando os fatores turno e produto, ocorre à falta de evidências que aprovem diferenças significativas. No entanto, para a interação turno*produto, a MANOVA fornece um valor menor que 5\%. Logo, é possível concluir que os valores de tempo das atividades, quando comparados entre si, utilizando interação turno*produto são diferentes, uma vez que os pressupostos desse teste foram atendidos.

Ao avaliar o tempo total gasto na operação de manutenção de ferramentas, onde as informações obtidas são providas do somatório de todos os tempos das atividades apresentadas no Quadro 2. O teste M de Box indica um nível de significância de 0,791 o que valida o pressuposto deste teste. Os resultados do teste MANOVA, são apresentados na Tabela 18, segundo o critério de Pillai. 
Tabela 18 - Resultados do teste MANOVA

\begin{tabular}{c|l|c|c|c}
\hline Item & \multicolumn{1}{|c|}{ Varíveis (ativich des) } & Turno $(p)$ & Produto $(p)$ & Turno * Produto $(p)$ \\
\hline 1 & Troca da bucha & & & \\
\cline { 1 - 2 } 2 & Troca de agulha & \multirow{2}{*}{0,084} & 0,015 & 0,059 \\
\hline 3 & Troca da faca & & & \\
\hline 4 & Troca de pino-guia & & & \\
\hline
\end{tabular}

$p$ - significância estimada.

Fonte: software SPSS versão 17 (2010)

O resultado do teste MANOVA, apresentado na Tabela 18, utiliza valores temporais referentes à efetivação de todas as atividades necessárias para substituir cada um dos quatro tipos de componentes. Contudo, esses resultados foram desenvolvidos considerando a variabilidade total do sistema, sendo este um ambiente de maior probabilidade de ocorrência de Erros Tipo I e II. Por causa disso, que a operação de manutenção foi dividida em atividades. Situação semelhante ocorre ao verificar o tempo total para a realização da operação de setup de ferramenta e abastecimento de bobina, onde os resultados são apresentados na Tabela 15.

\subsection{Sumário da Análise}

Com base nos resultados apresentadas na Tabela 15 e considerando o valor do CV, o Quadro 3 apresenta uma síntese de possíveis propostas de melhoria para as atividades pertencentes à operação de setup de ferramenta e abastecimento de bobina.

Quadro 3 - Síntese das melhorias necessárias

\begin{tabular}{|c|c|}
\hline Variáveis (atividades) & Melhorias propostas \\
\hline Buscar o carro hidráulico & Realização no "setup externo" \\
\hline $\begin{array}{l}\text { Tirar a ferramenta da máquina e por no carro } \\
\text { hidráulico }\end{array}$ & \multirow[t]{2}{*}{ Construção de uma bancada móvel } \\
\hline Aliviar o fuso & \\
\hline $\begin{array}{l}\text { Transporte da ferramenta até o setor de revisão } \\
\text { e colocá-la em cima da bancada }\end{array}$ & \multirow{2}{*}{ Realização no "setup externo" } \\
\hline $\begin{array}{l}\text { Pegar a ferramenta do novo lote e transportar } \\
\text { até a máquina }\end{array}$ & \\
\hline Trocar o curso & \multirow{4}{*}{$\begin{array}{l}\text { Padronização dos cursos/altura das } \\
\text { ferramentas } \\
\text { Utilização de fixadores funcionais } \\
\text { Alternativas que possibilitem a } \\
\text { centragem da ferramenta na mesa da } \\
\text { prensa, sem a necessidade de medição }\end{array}$} \\
\hline Descer fuso e fixar a ferramenta na prensa & \\
\hline & \\
\hline $\begin{array}{l}\text { Ajustar a altura do alimentador eletrônico e } \\
\text { chamar o programa que gerencia o passe da tira }\end{array}$ & \\
\hline $\begin{array}{l}\text { Subir o fuso, colocar a ferramenta na mesa } \\
\text { prensa e centrar }\end{array}$ & \multirow{3}{*}{ Não necessita de melhorias } \\
\hline $\begin{array}{l}\text { Abastecimento de bobina (representa todas as } \\
\text { atividades envolvidas nesta operação) }\end{array}$ & \\
\hline Ajustes finais & \\
\hline
\end{tabular}

Fonte: Autoria própria (2010) 
$\mathrm{Na}$ atividade de buscar o carro hidráulico, ocorre a falta de evidências que comprovem diferenças entre as médias ( $p>5 \%$ ) e o valor do CV é maior que 30\%. Uma alternativa para reduzir o valor de CV, seria a realização desta atividade somente no 'setup externo', conceituado por Shingo (1996) como todas as tarefas que podem ser realizadas quando a máquina está em operação, como por exemplo, transporte de ferramentas da máquina para a ferramentaria. Portanto, o transporte da ferramenta até o setor de revisão pode ser feita posteriormente a finalização da operação de troca de ferramenta (setup) e a busca da ferramenta do novo lote poderia ser feita momentos antes de finalizar o programa que esta sendo produzido. Esta prática não necessita de investimentos para ser feita e pode contribuir com a minimização de problemas futuros, com apenas a realização de treinamento no próprio local de trabalho.

Com base no resultado do teste de variância $(p>5 \%)$ e CV > 30\% para a atividade de aliviar o fuso, durante os estudos de cronoanálise foi observada a ocorrência de perdas, provocadas pela falta de organização dos materiais de trabalho, necessários para a execução desta atividade, fazendo com que o operador gaste tempo procurando os mesmos. Situação análoga ocorre na atividade de tirar a ferramenta da máquina e por no carro hidráulico, onde resultado do teste univariado ilustra diferenças significativas entre os tempos operacionais para todos os fatores. Diante da perda causada pela falta de organização dos materiais de trabalho, é sugerida a construção de uma bancada móvel, que possibilite a organização e fixação dos instrumentos (chaves, mareta, etc), eliminando a procura dos materiais. Esta ação pode contribuir para eliminar as diferenças encontradas entre os tempos operacionais.

Ao analisar as atividades de transporte da ferramenta até o setor de revisão e colocá-la em cima da bancada e pegar a ferramenta do novo lote e transportar até a máquina, é sugerida realocação destas duas atividades para serem realizadas no 'setup externo'.

Nas atividades de: trocar o curso, descer fuso e fixar a ferramenta na prensa e ajustar a altura do alimentador eletrônico e chamar o programa que gerencia o passe da tira, o teste de variância esboça a falta de padronização dos procedimentos entre os turnos $(p<5 \%)$. Essa questão merece atenção, pois essas atividades juntas somam 27,4\% do tempo total da operação de setup em média. Por causa disso, é importante a adoção de práticas que promovam a padronização dos tempos e a redução da variabilidade. Neste aspecto, sugere-se a aplicação dos seguintes métodos para reduzir a variabilidade, originários da TRF: (i) padronização dos cursos/altura das ferramentas; (ii) utilização de fixadores funcionais; e (iii) desenvolvimento de alternativas que possibilitem a centragem da ferramenta na mesa da prensa, sem a necessidade de medição.

A padronização do curso/altura da ferramenta é feita a partir do uso de calços (usinados e retificados) que são fixados na base ou na parte superior da ferramenta, dependendo da situação. A 
Figura 4 ilustra um exemplo de padronização de curso/altura de ferramenta, através do uso de calços fixados na base da ferramenta.

Figura 4 - Opção para padronizar o curso/altura das ferramentas

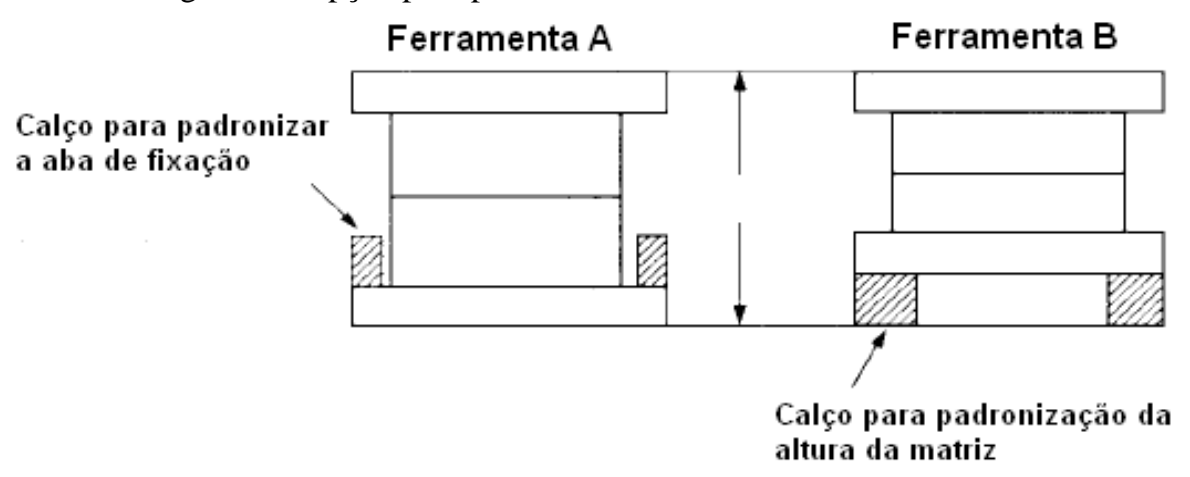

Fonte: Shingo (2000)

Além da eliminação da troca de curso obtida através da padronização de curso/altura, o uso de métodos funcionais para centrar e fixar a ferramenta na mesa da prensa pode contribuir para a redução da variabilidade nos tempos, provocado pela necessidade de medição e pela procura de parafusos, porcas e arruelas, que atualmente possuem diferentes e calibres. Nas Figuras 5 e 6 são apresentados exemplos de alternativas para fixação e centragem de ferramentas na mesa da prensa.

Figura 5 - Fixadores funcionais

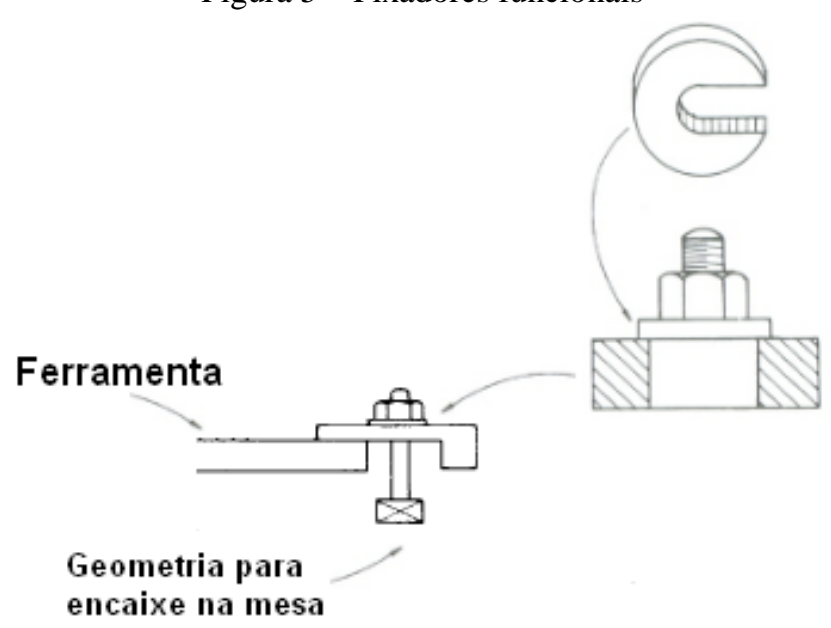

Fonte: Shingo (2000)

É ilustrado na Figura 6, o dispositivo de centragem que posiciona a ferramenta de forma alinhada, sem a necessidade de medições. Quando as extremidades desse dispositivo, adjacentes a linha $\mathrm{A}$, são aproximadas à estrutura da máquina, ocorrerá o paralelismo da ferramenta com a estrutura. $\mathrm{O}$ alinhamento da ferramenta é um dos requisitos para o funcionamento adequado do alimentador eletrônico. 


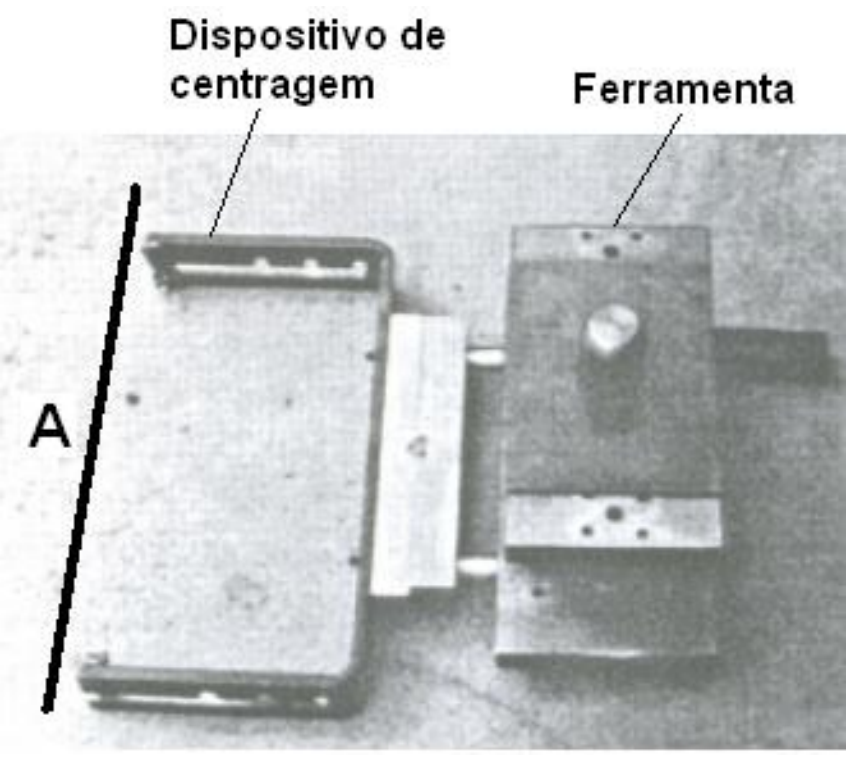

Fonte: Shingo (2000)

Ao analisar as atividades: subir o fuso, colocar a ferramenta na mesa prensa e centrar, e abastecimento de bobina, o teste de variância ilustra a falta de evidências que comprovem diferenças entre as médias $(p>5 \%)$, Na atividade de ajustes finais, o resultado do teste univariado exibe a ocorrência de diferenças significativas para o fator produto. No entanto, essas diferenças não afetam o dimensionamento do número de Kanbans, pois cada produto terá um número próprio de contêineres, calculado separadamente. Para essas 3 atividades, o valor de CV é menor que 30\%, portanto, é possível utilizar os valores temporais médios para dimensionar o número de cartões Kanban.

Ao avaliar os resultados obtidos nas Tabelas 16 e 17, relativas à operação de manutenção de ferramentas, ao ponderar o valor do CV, no Quadro 4 são ilustradas propostas de melhorias para as atividades. 
Quadro 4 - Síntese das melhorias necessárias

\begin{tabular}{|c|c|c|}
\hline \multirow{6}{*}{ 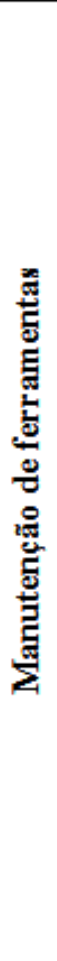 } & Buscar o carro hidráulico & $\begin{array}{l}\text { Definir um local padrão próximo a Linha } 2 \text {, } \\
\text { para deixar o carro hidráulico, eliminando a } \\
\text { necessidade de busca e procura pelo operador } \\
\text { Prioridade de uso para a Linha } 2\end{array}$ \\
\hline & $\begin{array}{l}\text { Tirar a ferramenta da máquina e por } \\
\text { no carro hidráulico }\end{array}$ & Construção de uma bancada móvel \\
\hline & $\begin{array}{l}\text { Transporte da ferramenta até o setor } \\
\text { de revisão e colocá-la em cima da } \\
\text { bancada }\end{array}$ & \multirow{2}{*}{$\begin{array}{l}\text { Estudar melhorias no layout ou controle dos } \\
\text { tempos através da cronoanálise }\end{array}$} \\
\hline & $\begin{array}{l}\text { Transporte da ferramenta já } \\
\text { consertada até a máquina }\end{array}$ & \\
\hline & Troca do componente danificado & $\begin{array}{l}\text { Desenvolver um grupo de estudo para } \\
\text { analisar a necessidade de desenvolver um } \\
\text { programa de treinamento para os } \\
\text { ferramenteiros, bem como melhorar a } \\
\text { organização dos materiais de trabalho }\end{array}$ \\
\hline & $\begin{array}{l}\text { Colocar a ferramenta na mesa, centrar } \\
\text { e fixar a ferramenta na prensa }\end{array}$ & $\begin{array}{l}\text { Aplicar a proposta feita nas seguintes } \\
\text { atividades: Trocar o curso, Descer fuso e } \\
\text { fixar a ferramenta na prensa e Ajustar a altura } \\
\text { do alimentador eletrônico e chamar o } \\
\text { programa que gerencia o passe da tira }\end{array}$ \\
\hline
\end{tabular}

Fonte: Autoria própria (2010)

Conforme apresentado no Quadro 2, é possível observar que ocorrem atividades similares nas duas operações. Um exemplo deste fato é a atividade buscar o carro hidráulico. Quando esta ocorre na operação de manutenção de ferramentas, uma alternativa de melhoria seria a definição de um local padrão próximo a Linha 2, para deixar o carro hidráulico, eliminando a necessidade de busca ou procura pelo operador. Cabe ressaltar a importância de priorizar a utilização deste equipamento para a Linha 2. Caso ocorra discrepância nas outras operações que utilizam este equipamento, as quais não são analisadas nesta pesquisa, deve-ser realizar um estudo para verificar a necessidade de compra de mais um carro hidráulico.

A proposta feita para a atividade de tirar a ferramenta da máquina e por no carro hidráulico para a operação de setup de ferramenta e abastecimento de bobina é mantida para a operação de manutenção de ferramentas.

Para a atividade de transporte da ferramenta até o setor de revisão e colocá-la em cima da bancada o teste de Kruskal-Wallis mostra diferenças significativas entre os fatores turno e produto. $\mathrm{Na}$ atividade transporte da ferramenta já consertada até a máquina que conforme apresentado no Quadro 2 é similar a atividade pertencente a operação de setup de ferramenta e abastecimento de bobina, que é a pegar a ferramenta do novo lote e transportar até a máquina. Para esta atividade, o teste apresenta diferenças significativas para o fator turno. Com base nos resultados obtidos para essas duas atividades, ressalta-se a importância de promover melhorias no layout, objetivando 
reduzir a distância percorrida de transporte da ferramenta, como meio de reduzir a variabilidade. No entanto, outra alternativa possível, seria o controle dos tempos através da cronoanálise.

Especificamente para as atividades que envolvem a troca do componente danificado, o teste MANOVA apresenta a falta de evidências que confirmem diferenças para o fator turno $(p=0,286) \mathrm{e}$ produto $(p=0,141)$. No entanto, o teste apresenta a ocorrência de diferenças significativas na interação turno* produto $(p=0,031)$. Ao analisar o valor do CV para cada componente, considerando os 4 tipos de produtos, é obtido um valor menor que 30\%. Com base no resultado que indica diferenças significativas na interação turno*produto, argumenta-se a necessidade a priori de desenvolver um grupo de estudo visando analisar a necessidade de desenvolver um programa de treinamento para os ferramenteiros $\left(1^{\circ}\right.$ e $2^{\circ}$ turnos $)$ visando padronizar os métodos utilizados para substituição dos componentes, bem como melhorar a organização dos materiais de trabalho.

Ao analisar a atividade de colocar a ferramenta na mesa, centrar e fixar a ferramenta na prensa o valor do CV para os produtos 1, 2 e 3 é maior que $30 \%$, e o resultado da análise multivariada relata a ocorrência de falta de evidências que confirmem diferenças nos valores temporais, conforme apresentado na Tabela 16. Aqui, as propostas apresentadas nas atividades de: trocar o curso, descer fuso e fixar a ferramenta na prensa e ajustar a altura do alimentador eletrônico e chamar o programa que gerencia o passe da tira, podem contribuir para a simplificação e redução do CV.

É válido salientar que uma vez implantadas as propostas de melhoria descritas nos Quadros 3 e 4, é necessária a realização de um novo estudo, tendo como meta, a análise da variância e análise do grau de CV, obtidos pós-implantação das melhorias, desta forma, é confirmada a eficiência das propostas no que tange a redução da variabilidade no sistema produtivo. Uma vez confirmada à redução da variabilidade, é plausível a obtenção das vantagens do uso do Kanban, caso contrário, é possível nortear as ações específicas para as atividades que ainda necessitam de melhorias para reduzir a dispersão dos tempos.

\section{Considerações Finais}

A presente pesquisa teve como objetivo propor uma discussão sobre a utilização de técnicas estatísticas para substanciar a análise de pré-implantação de um sistema Kanban, feita a partir de um estudo realizado em uma linha de estamparia, onde o foco é a implantação do sistema Kanban para auxiliar nas atividades referentes à Programação da Produção. Com base neste aspecto, foi utilizado testes de Análise de Variância, objetivando detectar a ocorrência de diferenças significativas superiores a 0,5 dp cada uma das atividades pertencentes as operações de: setup de ferramenta; abastecimento de bobina; e manutenção de ferramentas. A partir dos resultados obtidos 
com esses testes e considerando o Coeficiente de Variação, foram desenvolvidas propostas que podem contribuir com a redução da variabilidade, nas atividades onde essa questão é necessária.

A filosofia do Kanban está sendo incorporada na empresa e, para que os benefícios oferecidos por ela sejam alcançados, a realização de análises de pré-implantação, para verificar a necessidade é importante para promover melhorias sustentáveis nas operações e no processo, antes de implantar o Kanban. As principais vantagens do uso da abordagem apresentada neste contexto dizem respeito ao auxílio na definição das atividades que realmente carecem de ações de melhoria, visando atingir a redução das dispersões do sistema, gerando foco para a ação e segurança sobre as mudanças de política de produção realizadas.

\section{Abstract}

This paper show a discussion regarding the apply of statistical techniques to analyze the predeployment of a Kanban system, which will have as its main attribute, assist in activities related to production scheduling and inventory control in a stamping cell. The test, carried out with 4 types of components with higher demand, would be to assess the benefits of applicability of the tool and also trained the staff involved. From the results of tests provided by analysis of variance and considering the coefficient of variation of each activities madden by operations: tools's setup; slitter's supply; and tool's maintenance are developed proposals that seek to reduce the variability in activities that significant differences are seem in the factors like: shift, product and shift*product, before calculating the number of Kanban's card of system.

Key-words: Kanban systems; Variance Analysis; Non-parametric Statistics.

\section{Referências}

ANTUNeS, J. et al. Sistemas de Produção: Conceitos e Práticas para Projeto e Gestão da Produção Enxuta. 1. ed. Porto Alegre: Bookman, 2008.

ANTUNES, J. A. V. J. Comparação crítica entre os princípios gerais que regem a teoria das restrições (TOC) e a teoria que sustenta a construção dos sistemas de produção com estoque zero (SPEZ): no sentido da construção de uma teoria geral das melhorias no processo. In: ANANPAD, 1998.

BISQUERRA, A. R. : CASTELLÁ SARRIERA, J.; MARTÍNEZ, F.. Introdução à estatística: enfoque informático com o pacote estatístico SPSS. Porto Alegre: Artmed, 2004.

BONVIK, A. M.; GERSHWIN, S. B.; TROXEL, D. E. Operating high variability manufacturing systems. Oper. Res. Center, MIT, Cambridge, 1995.

CONTADOR, J. L.; CONTADOR, J. C.; CARVALHO, M. F. H.; NETO, P. L. O. C. Sistema Kanban para fábrica de tintas. Revista de Administração e Inovação, São Paulo. 2005.

CORRÊA, H. L.; GIANESI, I. G.N.; CAON, M. Planejamento, programação e controle da produção. São Paulo: Atlas, 2001.

HAIR JUNIOR, J. F.; ANDERSON, R. E.; TATHAM, R. L.; BLACK, W. C. Análise multivariada de dados. 9. ed. Porto Alegre: Bookman, 2009.

HOPP, W. J.; SPEARMAN, M. L. Factory Physics: foundations of manufacturing management. 2. ed. Boston: McGraw-Hill, 2000. 
KRISHNAMURTHY, A.; SURI, R. Performance analysis of single stage Kanban controlled production systems using parametric decomposition. Springer Science, 2006.

LAGE JUNIOR, M.; GODINHO FILHO, M. A utilização do sistema Kanban frente às novas condições do ambiente competitivo. In: XIII Simpósio de Engenharia de Produção, São Paulo. Anais... São Paulo, 2006.

MARTINS, P. G.; LAUGENI, F. P. Administração da produção. São Paulo: Saraiva, 2002.

OHNO, T.. O Sistema Toyota de Produção: Além da Produção em Larga Escala. Porto Alegre: Bookman, 1997.

ROTHER, M.; SHOOK, J. Aprendendo a Enxergar: Mapeando o fluxo de valor para agregar valor e eliminar o desperdício. São Paulo: Lean Institute Brasil, 1999.

SANCHES, A. L.; MARINS, F. A. S.; MONTEVECHI, J. A. B.; RIBEIRO, D. A. Dimensionamento de Kanban Estatístico por Simulação de Monte Carlo Utilizando o Software Crystal Ball. In: Simpósio de Excelência em Gestão e Tecnologia, 2007, Resende-RJ. Anais... Resende-RJ, 2007.

SHINGO, S. O Sistema Toyota de produção: do ponto de vista de engenharia de produção. 1. ed. Porto Alegre: Bookman, 1996.

SHINGO, S. Sistema de troca rápida de ferramenta. Porto Alegre: Bookman, 2000.

SIEGEL, S. Estatística não-paramétrica: para as Ciências do comportamento. São Paulo: McGraw-Hill, 1975.

SLACK, N. et al. A Administração da produção. 1. ed. São Paulo: Atlas, 1997.

SUWANRUJI, P.; ENNS, S. T. Evaluating the effects of capacity constraints and demand patterns on supply chain replenishment strategies. International Journal of Production Research, v. 44, n. 22, nov. 2006.

YIN, R. K. Estudo de caso: planejamento e métodos. Porto Alegre: Bookman, 2001.

\section{Dados dos autores:}

Nome completo: Isaac Pergher

Filiação institucional: Universidade do Vale do Rio dos Sinos - UNISINOS - São Leopoldo Brasil

Função ou cargo ocupado: Professor

E-mail:eng.isaac@hotmail.com

Nome completo: Guilherme Luís Roehe Vaccaro

Filiação institucional: Universidade do Vale do Rio dos Sinos - UNISINOS - São Leopoldo Brasil

Departamento: Mestrado em Engenharia de Produção e Sistemas e do Mestrado Profissional em Gestão e Negócios

Função ou cargo ocupado: Professor

Endereço: Universidade do Vale do Rio dos Sinos, Unidade Acadêmica de Pesquisa e Pós Graduação. Avenida Unisinos, 950 - Cristo Rei, CEP:93022-000 - São Leopoldo, RS - Brasil Telefone para contato: (51) 35911100

E-mail: guilhermev@unisinos.br

Enviado em: 27/07/2011

Aprovado em: 10/05/2012 